\title{
La cultura mediática del profesorado universitario en México
}

institucional.us.es/ambitos/

\section{Raquel Martínez Sanz}

Universidad de Valladolid

raquel.martinez.sanz@uva.es

\section{Dafne Calvo}

Universidad de Valladolid

dafnecal@gmail.es

English Version: The media culture of university teachers in Mexico.

\section{Resumen}

Entre los principales problemas que acechan al panorama mediático en México se encuentran la concentración empresarial y la insuficiente autorregulación. Sin embargo, la aparición de Internet -y con él de nuevos medios y soportes- supone una esperanza para el fortalecimiento democrático donde los docentes juegan un

papel fundamental. A través de la técnica de la encuesta, aplicada en dos universidades mexicanas (BUAP y La Salle) se examina cómo se informa el profesorado, un colectivo sobre el que recae la tarea no solo de transmitir conocimientos sino de servir de referente para su alumnado, y se identifican las

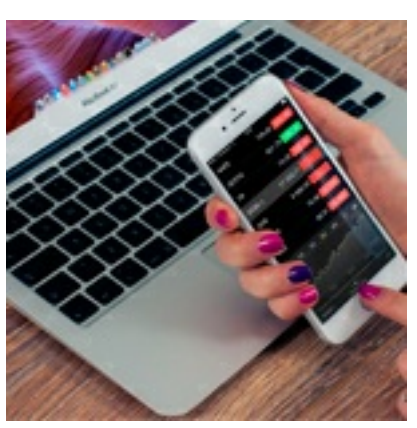

\section{Palabras clave}

Consumo de medios, Internet, interactividad, México.

\section{Abstract}

The main problems that of Mexican media are corporate concentration and insufficient self-regulation. However, the emergence of the Internet and also new social media and electronic devices is a hope for strengthening democracy in the American country. In this context, communication teachers play a key role. The aim of this article is to analyze media culture of Communication professors in Mexico, as their tasks are not only limited to teach, but also to be a model of behavior. We conduct a survey in two universities (BUAP and La Salle). Questionnaire asks about their information interests, consumption habits and forms of participation in mass media.

\section{Keywords}

Media consumption, Internet, interactivity, Mexico.

\section{INTRODUCCIÓN}

La fuerte dependencia económica e ideológica que presentan los medios de comunicación mexicanos condiciona su desarrollo (Fernández Christlieb, 2005; Moraes \& Killmann, 2011) y fragua la desconfianza que los ciudadanos sienten hacia buena parte de las instituciones (CESOP, 2014). Ese hastío generalizado echa a los ciudadanos a la calle para demandar cambios significativos en la gestión de los recursos públicos poniéndose, en reiteradas ocasiones en entre dicho, el papel «vigilante» de los medios de comunicación.

Si bien es cierto que las Tecnologías de la información (TIC), representadas a través de Internet, aspiran a superar las carencias del actual panorama mediático en México facilitando el flujo comunicativo entre usuarios 
(Pasquali, 2011), la brecha digital, que afecta tanto al acceso como a la calidad del uso proferido a los dispositivos, supone un freno a la evolución (Barja \& Gligler, 2009). De ahí que la educación y el papel jugado por los docentes resulte capital al constituirse en ejemplos de comportamiento para sus alumnos.

A partir de la situación descrita, surge esta investigación, enmarcada dentro del Proyecto de Innovación Docente reconocido por la Universidad de Valladolid con el título Evaluación y Desarrollo de Metodologías Docentes en Comunicación y Competencia Mediática, que pretende una mejora de la educación en Comunicación a partir del uso de metodologías vinculadas a las nuevas tecnologías. Como paso previo, se estima imprescindible conocer desde qué situación parte uno de los colectivos directamente implicados, los docentes.

El principal objetivo del estudio se concreta en reconocer la cultura mediática del profesorado universitario especialista en Comunicación, ejemplificado en sus hábitos de consumo de información. Además, y dada la relevancia que han adquirido las TIC se pone especial atención a la intensidad (frecuencia) con la que el docente manipula dispositivos como el teléfono móvil, la tableta o el ordenador con el fin de estar al día de la actualidad, lo que denota un dominio de los mismos -elemento cuya ausencia ahonda en la brecha digital (ONU, 2014)-. También, y dada su faceta de especialistas, nos preocupa la opinión que a los profesores mexicanos les merece la calidad de cada uno de los medios de comunicación masivos (prensa, radio y televisión) y las formas más habituales de interacción que practican.

Los resultados, obtenidos a través de la técnica de la encuesta, provienen de las respuestas facilitadas por el personal de dos centros universitarios mexicanos: la Benemérita Universidad Autónoma de Puebla y la Universidad La Salle, en la sede de Ciudad de México.

\subsection{Una población desencantada}

El último estudio elaborado por CESOP (2014), el Centro de Estudios Sociales y de Opinión Pública, y avalado por la LXII legislatura de la Cámara de Diputados, pone de manifiesto la escasa confianza que los mexicanos depositan en las instituciones, tanto de índole política, administrativa como mediática. Sirva como ejemplo que más del $60 \%$ de la población declara «poca» o «nula» confianza en el Presidente de la República, los jueces, la policía o la prensa. En el lado opuesto, la familia, los amigos y las universidades públicas son las instituciones que concentran una mayor seguridad.

Además, desde hace unos años, el país experimenta un incremento en el número de protestas que evidencian el hastío social. Protestas que en muchos casos tienen como nota común la denuncia de la cercanía y concomitancia de los medios de comunicación con los poderes políticos y económicos, dejando de lado su labor observadora y crítica de la realidad (Fernández Christlieb, 2005; Moraes \& Killmann, 2011). León Vázquez (2001) recuerda que el periodismo «contribuye a configurar el escenario de lo público mediante la visibilización de ciertos temas y actores y el ocultamiento de otros» (2001: 65). De ahí que sin independencia, la función social del periodismo queda diluida cuando no dirigida.

Los estudios sobre hábitos de consumo cultural además de identificar los intereses, comportamientos y repercusiones en los consumidores proponen mejoras dirigidas a elevar la calidad de la oferta cultural. Sin embargo, Rosas Mantecón (2002) encuentra una falta de apoyo institucional en México para llevar a efecto cambios significativos. Además, denuncia que, en otras tantas ocasiones, las técnicas empleadas son utilizadas como instrumento para legitimar la gestión y las políticas de contenido seguidas por el comité de turno. En la raíz del problema, esta investigadora señala la falta de organizaciones civiles que presionen para que los derechos de los ciudadanos como espectadores y consumidores se cumplan.

En este sentido, el reto de Internet es romper con la tiranía de los medios dependientes económica e ideológicamente y facilitar una mayor libertad en el flujo comunicativo de los ciudadanos (Pasquali, 2011). Meneses Rocha (2011) muestra como ejemplo de las nuevas posibilidades de la Red el Contingente MX, una iniciativa ciudadana que busca la rendición de cuentas por casos como los feminicidios. Sin embargo, esta misma autora reconoce que, de forma general, «los medios convencionales que han extendido su negocio a la Internet, más que preocupación por articular una agenda que responda a las necesidades ciudadanas, por 
encima de los intereses políticos y empresariales, demuestran su interés por conquistar mercados de lectores y audiencias jóvenes» (2011: 370).

Como consecuencia, se genera una corriente de interés académico por las nuevas tecnologías orientada a analizar la capacidad de estas para logar un cambio de paradigma comunicativo afectando irremediablemente también al plano político. Esta transformación, como manifiesta Pasquali, tendrá su repercusión en el resto del continente:

«En este momento, y pese a sus complejidades, México es el país de la región con la masa más fuertemente organizada e institucionalizada con incansables luchadores por la dignidad en comunicación. Sus logros se convertirán en modelos y ejemplo para muchos. Latinoamérica está pendiente de sus éxitos» (2011: 21).

\subsection{El panorama mediático en México}

El panorama mediático en México adolece desde hace décadas, de dos graves problemas: la concentración empresarial (Huerta-Wong \& Gómez, 2013; Gutiérrez \& López, 2014) y la ineficiente regulación de la Administración pública (Trejo Delarbre, 2012).

A pesar de que buena parte de las industrias culturales relacionadas con los medios de comunicación se sostienen con capital privado, es una obligación de los estados velar por el interés general y regular su funcionamiento y operatividad en aras de evitar monopolios, principalmente de tipo ideológico dada la fuerte capacidad de influencia que los medios tienen sobre la sociedad (Sánchez Ruíz, 2005).

En el caso concreto de México, Trejo Delarbre (2012) sentencia que la normativa actual reguladora de los medios de comunicación, no contribuye ni a dotarlos de calidad ni a instaurar una clara diversidad ideológica. Buen ejemplo de ello es la Ley Federal de Radio y Televisión de 1960 que reguló la radiodifusión en todo el territorio (1). Esta ley deja constancia de que el espacio electromagnético pertenece al Estado y por tanto recae en él la tarea de ordenarlo y distribuirlo. Así pues, las licencias de radio y televisión expedidas para autorizar el uso del espacio, además de estar en manos de organismos directamente controlados por el Gobierno Central, han sido concedidas bajo una manifiesta arbitrariedad premiando a aquellos solicitantes más afines ideológicamente frente a los que no lo eran o mostraban mayor oposición. Esta constante malversación es el caldo de cultivo más propicio para la concentración empresarial (Esteinou Madrid, 2000).

\section{El Informe Anual de la Comisión Interamericana de Derechos Humanos 2010 (Organización de los Estados} Americanos, 2010) puntualiza que esta desvirtualización del sistema atenta directamente contra la pluralidad y la libertad de expresión.

Los ejemplos más evidentes implican a la radio y a la televisión. El investigador Gabriel Sosa Plata (2011) contabiliza hasta 1600 estaciones de radiodifusión, de las cuales 1235 tienen licencia para operar de manera comercial, mientras que solamente 365 (el 23\%) son estaciones no comerciales que pertenecen a instituciones sin afán de lucro (principalmente del gobierno federal y de los gobiernos locales). La concentración de frecuencias de radio en pocas manos se aprecia en la circunstancia de que al menos el $70 \%$ de las estaciones comerciales, casi 8 de cada 10 emisoras de todo el país, son operadas -en propiedad o mediante la afiliaciónpor tan solo 10 grupos radiofónicos distintos (2).

Sin embargo, es la televisión el medio que se concentra en menos manos. De los 863 canales de televisión identificados por Trejo Delarbre (2012) el 62\% (532 canales) están concesionados a Televisa y Televisión Azteca. El resto obedece a licencias otorgadas a gobiernos locales, con baja potencia de radio y fuertemente politizados, y a instituciones educativas, principalmente universitarias. Con este perfil, la concesión de mayor impacto es gestionada por el Instituto Politécnico Nacional bajo el nombre de Canal 11.

El resultado de todo esto es que la información televisiva, salvo excepciones, «no ha permitido la expresión de las necesidades de los grandes grupos sociales a través de esta; y en consecuencia, no se ha dedicado sustantivamente a crear conciencia sobre los principales problemas que debemos resolver para sobrevivir» (Esteinou Madrid, 2000: 12). Así pues, la conciencia social es incompleta y las posibilidades de desarrollo nacional, menores. 
Otro importante fenómeno que contribuye a la concentración y este al monopolio es la diversificación del negocio. De pasar a dominar un medio concreto, las empresas más potentes añaden a su gestión otras industrias culturales orientadas a la información y al entretenimiento. Los casos más representativos los constituyen nuevamente Televisa y Televisión Azteca que, además de canales de televisión, poseen editoriales, radios y productoras de cine, música y televisión y participan de equipos de fútbol y de compañías de telecomunicaciones (Villamil, 2010). Huerta-Wong \& Gómez (2013) relatan que durante el tiempo que el Grupo Televisa, con sus tres señales nacionales (2, 5 y 9 ) y una metropolitana (4), no puso en cuestionamiento las actuaciones del partido gobernante (PRI) obtuvo carta blanca para expandirse y obtener suculentos rendimientos, reinvirtiendo buena parte de lo ganado en nuevas industrias que acabarían por hacerle controlar todo el proceso de producción y distribución de contenidos audiovisuales.

Y tomando como punto de referencia la prensa impresa, emerge otra característica escasamente favorecedora para los medios mexicanos: su tendencia a la centralidad (Sánchez Ruíz, 1987), es decir a ser emitidos y distribuidos mayoritariamente desde y para las grandes ciudades, principalmente Distrito Federal. Así pues, la concentración no solo se atisba en la propiedad sino también desde los lugares desde donde se crean.

Huerta-Wong \& Gómez (2013) recuerdan que la industria periodística en México se enfrenta a un doble reto: las bajas cifras de lectura (3), a pesar de los esfuerzos por hacer extensible la educación formal; y la desconfianza hacia las informaciones transmitidas por el medio impreso dada su tendencia a mover el agua del partido en el poder. A pesar de todo, Sánchez Ruiz (2005: 403) sí observa una transición, más notable en la capital que en las provincias, consistente en la configuración de una prensa que ha pasado de ser predominantemente "gobernista y acrítica» y dependiente económicamente de las ayudas del gobierno -en formato o no de publicidad institucional-, a una relativamente más plural, independiente y crítica, aunque eso sí, con una cuota de lectores mínima.

\subsection{Procesos de digitalización y educación en TIC}

Las tecnologías de la información (TIC) aplicadas a los medios de comunicación además de facilitar el trabajo periodístico, suponen una mejora para el usuario que ve cómo se multiplica el número de vías de acceso a la información, se normaliza la participación activa y se incorpora la personalización el consumo de contenidos. Sobre esta base hay que tener en cuenta que los procesos de digitalización y sobre todo, sus efectos varían en función del medio y del país (Legorbur Hortelano, 2013).

En México, la penetración de Internet afecta al 51\% de la población (AMIPCI, 2015) y aunque la Organización de las Naciones Unidas (2014) aplaude el alto índice de desarrollo del gobierno electrónico, el país presenta una implementación deficitaria de servicios digitales, pues solo 9,83 habitantes de cada 100 tienen instalada banda ancha (4). Para la ONU (2014) estos resultados tienen una explicación parcial en el precio prohibitivo de Internet -uno de los más caros de toda América Latina- que trae como consecuencia que el $40 \%$ de los usuarios solo accedan a la Red en espacios públicos.

Barja \& Gligler (2009) señalan que para alcanzar el acceso universal a la sociedad de la información hay que superar, entre otras cuestiones, la falta de competencias para manejar los dispositivos y obtener el máximo potencial. Como consecuencia, buena parte de las políticas TIC puestas en marcha por los diferentes países se vinculan con la educación, definiendo estrategias que alienten su uso entre el profesorado y sus alumnos (Lugo, 2010).

El reto no se encuentra solo en dotar de dispositivos tecnológicos a los centros educativos sino en integrar a la tecnología en la educación ciudadana para alcanzar una participación civil igualitaria (Schalk Quintanar, 2010:

13). Desde la perspectiva de la comunicación, la educación digital fortalece competencias como la capacidad de identificar información relevante, de analizar las implicaciones de las comunidades virtuales o de hacer efectiva la convergencia periodística, a fin de «comprender y analizar el sentido de la participación en la web y en la telefonía móvil» (Aparici \& Osuna, 2010: 315).

En esta situación el docente, como reconoce la UNESCO (2013), representa la influencia externa más importante en el aprendizaje en el aula y en la educación en general. Entre sus muchos cometidos, los profesores además de asegurar que los alumnos apliquen un uso correcto a la tecnología han de estar 
capacitados para transmitir conocimientos a través de ella (UNESCO, 2013). Esta situación hace que se conviertan en modelos y referentes (Lagunes-Domínguez et al., 2015) sobre el que el alumnado posa su mirada.

\section{METODOLOGÍA}

Para cumplir con el principal objetivo marcado por esta investigación: analizar el consumo mediático del colectivo docente universitario especializado en Comunicación en México se recurre a la encuesta como método fundamental de observación directa de un aspecto de la realidad social (García \& Llopis, 2015).

La encuesta, distribuida de forma anónima y en soporte online, fue facilitada a todos los profesionales docentes de la Licenciatura en Comunicación de las universidades de La Salle, en su sede de la capital mexicana, Distrito Federal, y de la Benemérita Universidad Autónoma de Puebla (BUAP).

El cuestionario, compuesto de 34 preguntas, queda dividido en seis grandes bloques temáticos. El primero de ellos tiene como propósito conocer, a grandes rasgos, cuál es el medio más consumido, qué sistemas de preferencia usa el profesorado para informarse y la calidad y problemas que este les atribuye. Los siguientes cuatro bloques se focalizan en un medio concreto, a saber: prensa, radio, televisión e Internet, con preguntas que, aunque no idénticas en todos los bloques, sí tienen los mismos propósitos: identificar las temáticas preferidas, los momentos del día de mayor consumo, las situaciones y/o compañía más habitual durante dicho consumo, los medios y/o programas más seguidos, el soporte de preferencia y los mecanismos de participación más utilizados por el docente para interactuar con cada uno de los medios. Por último, el bloque 6 introduce dos cuestiones relacionadas con los rasgos sociodemográficos del encuestado: género y edad, y universidad de procedencia.

El diseño y composición de la encuesta forma parte del Proyecto de Innovación Docente: Evaluación y Desarrollo de Metodologías Docentes en Comunicación y Competencia Mediática, dirigido por las profesoras de la Universidad de Valladolid, Dra. Eva Campos y Dra. Marta García. En esta Universidad fue aplicada por primera vez la encuesta durante el curso académico 2014/2015 (Martínez Sanz et al., 2016) para, seguidamente, replicarse en México: en 2015, en la Universidad La Salle y en 2016, en la BUAP.

Entre los motivos que llevaron a la elección de estas dos universidades se destaca que en ambos centros se oferta la misma titulación: Licenciatura en Comunicación y que se dispone de una plantilla de docentes muy pareja, 50 en La Salle y 62 en la BUAP. También resultó determinante que sus sedes ocuparan un espacio físico radicalmente diferente: el primero, en la capital del país, con una población de 8,8 millones de habitantes, lo que representa el $7,4 \%$ del total de la población, mientras que la BUAP se localiza también en una ciudad, en su caso, capital del estado de Puebla, con un millón y medio de habitantes, el 1,2\% (5).

Los datos obtenidos fueron tratados en una base de datos del programa SPSS, herramienta de análisis estadístico especialmente útil para técnicas de investigación como la encuesta (Humanes, 2005), a través del cual se llevó a cabo un análisis estadístico univariante y bivariante, basado en recursos comunes de la estadística: tablas de frecuencia y tablas de contingencia.

Por lo que respecta a las características sociodemográficas de la muestra, del total de docentes que componen la plantilla de La Salle y la BUAP en el área de Comunicación (118 sujetos), respondieron a la encuesta el $60,2 \%$. De estos, el $43,7 \%$ eran hombres y el $56,3 \%$, mujeres y aproximadamente, la mitad de los encuestados $(52,1 \%)$ tenían una edad comprendida entre los 40 y los 50 años. La siguiente franja mayoritaria se sitúa entre los 30 y los 40 años, mientras que en los extremos (de 20 a 30 años o más de 60) el número de sujetos es insignificante $(4,2 \%)$.

Gráfico 1. Características sociodemográficas de la muestra 


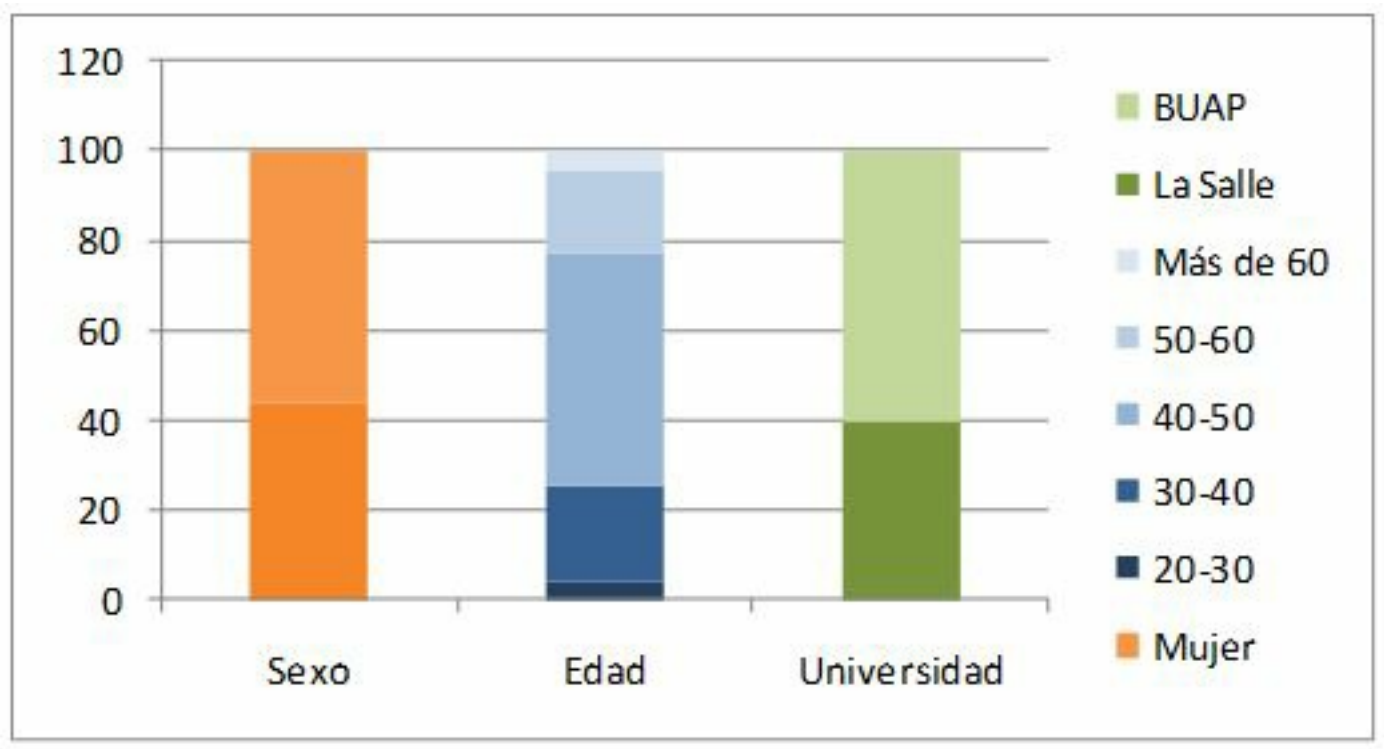

Fuente: elaboración propia

\section{ANÁLISIS DE LOS RESULTADOS}

De la realización de la encuesta se extrae que el docente mexicano es un consumidor asiduo y de consulta diaria, de prensa $(40,8 \%)$, televisión $(43,7 \%)$, radio $(46,5 \%)$ y círculo de amigos y conocidos $(47,9 \%)$ con la finalidad de informarse. Es más, tan solo un 2,8\% para el caso de la prensa, un 4,2\% para la televisión y un 7\% para la radio declara no utilizar estos medios. Por lo que respecta a la consulta de magazines y revistas esta se dilata en el tiempo siendo la opción mayoritaria la que reconoce acudir a ella en varias ocasiones al mes $(42,3 \%)$.

Si nos atenemos al soporte, es casi unánime la preferencia del profesorado universitario en Comunicación por el soporte tradicional a la hora de consumir televisión y radio. Los resultados no dejan lugar a dudas: el $94,4 \%$ y el $70,4 \%$, se decantan por el aparato analógico radiofónico y televisivo, respectivamente. En el caso de la prensa impresa se impone el ordenador como mecanismo de visionado $(35,2 \%)$-ya sea sobremesa o portátil-. Y nuevamente Internet despunta cuando se trata de informarse a través de círculos de amigos o conocidos. Para esta situación, la opción mayoritaria es el móvil, en el $36,6 \%$ de los casos, seguida del ordenador $(26,8 \%)$.

\subsection{La prensa impresa, para todos los temas y comentada en redes sociales}

Si bien es cierto que las primeras preguntas demuestran el interés diario de los docentes por informarse a través de la prensa, un análisis más minucioso revela que este target consulta todos los días prensa nacional en el $45,1 \%$, mientras que en el caso de la prensa de origen internacional, regional y local los resultados son muy parejos rondando el 30\%, lo cual corrobora el interés constante por todo tipo de información.

Gráfico 2. Hábito de consumo según el tipo de prensa 


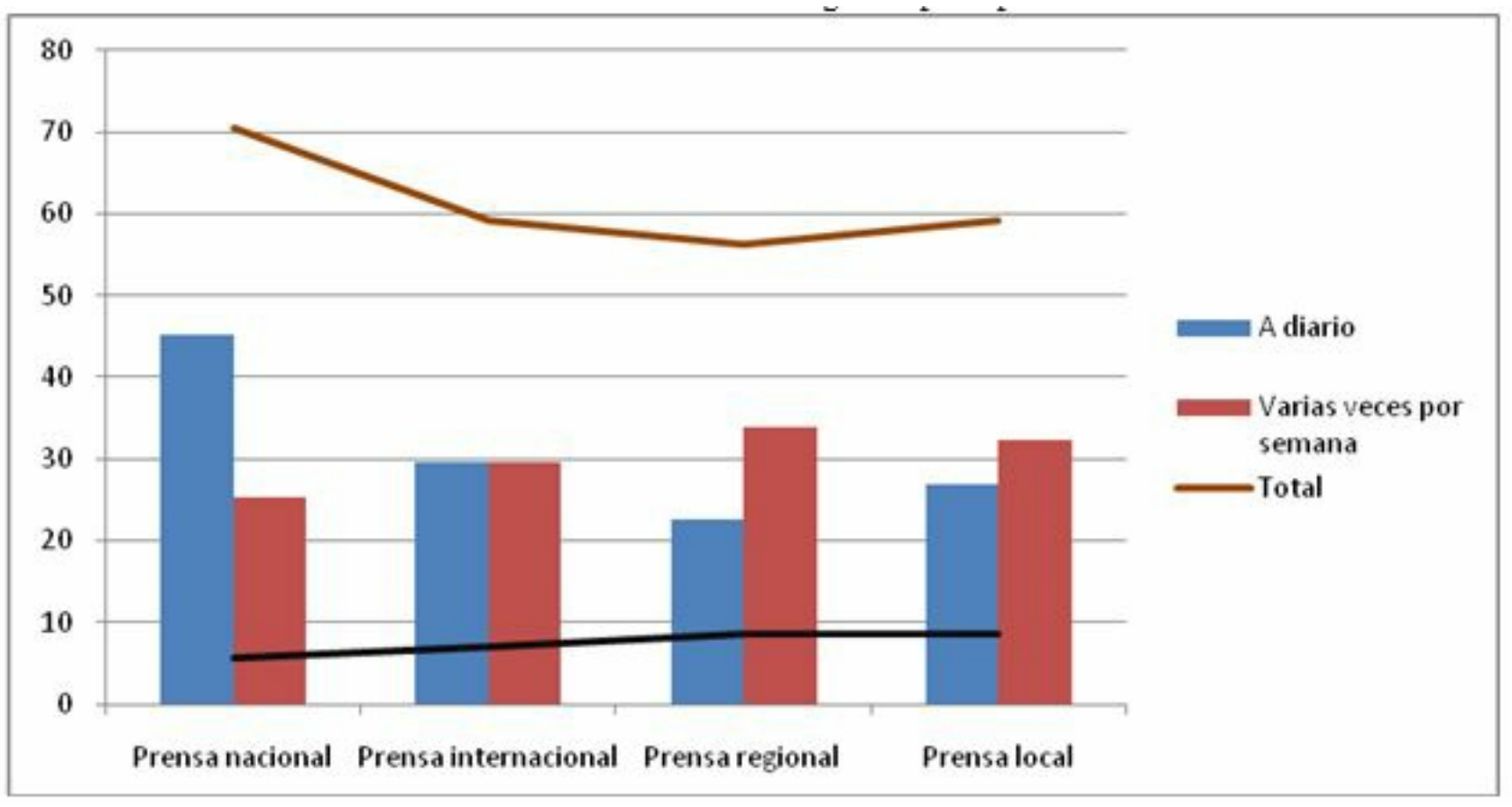

Fuente: elaboración propia

De la amplia oferta de cabeceras, el profesorado universitario asegura leer con más asiduidad La Jornada marcada como primera opción de preferencia por el 26,6\% de los encuestados-, El Universal-el más nombrado como segunda opción de preferencia-y Reforma.

Cuando de lo que se trata es de verificar la percepción de la calidad aportada por la prensa impresa, más de la mitad la califica como buena o muy buena $(52,1 \%)$, mientras que solo para menos del $10 \%$ merece el calificativo de mala o muy mala. El colectivo docente señala los escasos medios económicos con los que cuentan las redacciones $(32,4 \%)$ y el bajo nivel profesional de los trabajadores $(26,8 \%)$ como los principales frenos al desarrollo de este medio.

En cuanto a la temática, las secciones que atraen un mayor interés son política nacional, que despunta por encima del resto al haber sido marcada como la primera preferencia por el 52,1\%; seguida de política internacional, que se impone como segunda preferencia para el $35,2 \%$ de los encuestados; y cultura.

De toda la muestra consultada, el $80,3 \%$ reconoce haber interactuado alguna vez con el medio impreso. De los mecanismos participativos propuestos (gráfico 3), sobresalen las redes sociales como el más utilizado por el docente en Comunicación: bien para compartir noticias ya publicadas $(75,4 \%)$ o para hacer un comentario sobre alguna información. En este caso, la red social más empleada es Facebook, mencionada por el 52,6\%, frente a Twitter que tan solo lo fue en el $21 \%$.

Gráfico 3. Mecanismos de participación en prensa 


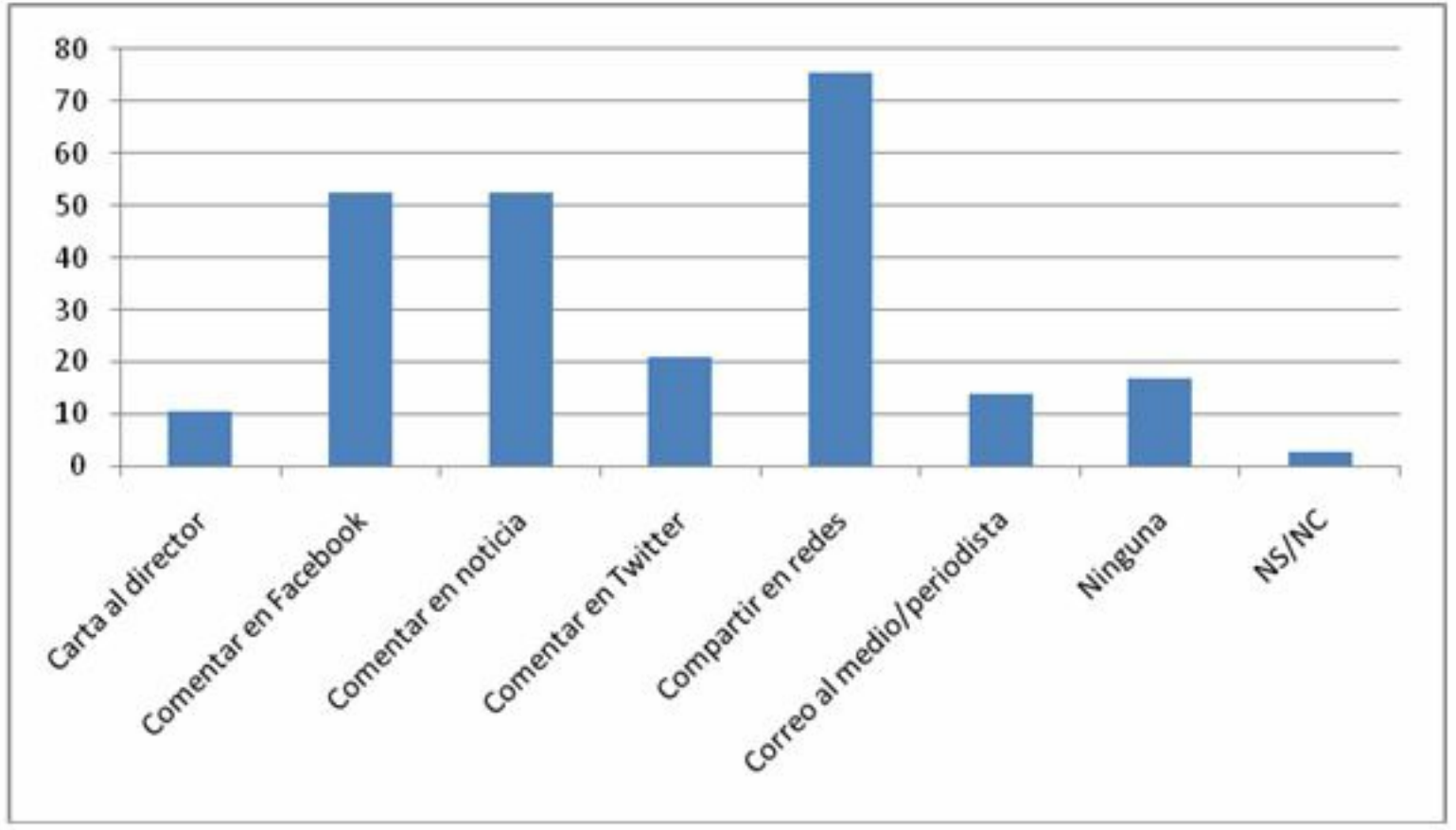

Fuente: elaboración propia

\subsection{La radio, un medio matutino para información generalista en el transporte}

La radio se presenta como una fuente de información fundamental para el profesorado universitario de México y es que un $45,1 \%$ de los encuestados afirma conocer siempre la realidad mediante este medio de comunicación. Además, su consumo resulta frecuente en el tiempo: un $46,5 \%$ del profesorado de La Salle y la BUAP escuchan la radio a diario y un $28,2 \%$ varias veces a la semana.

Gráfico 4. Frecuencia de escucha de la radio

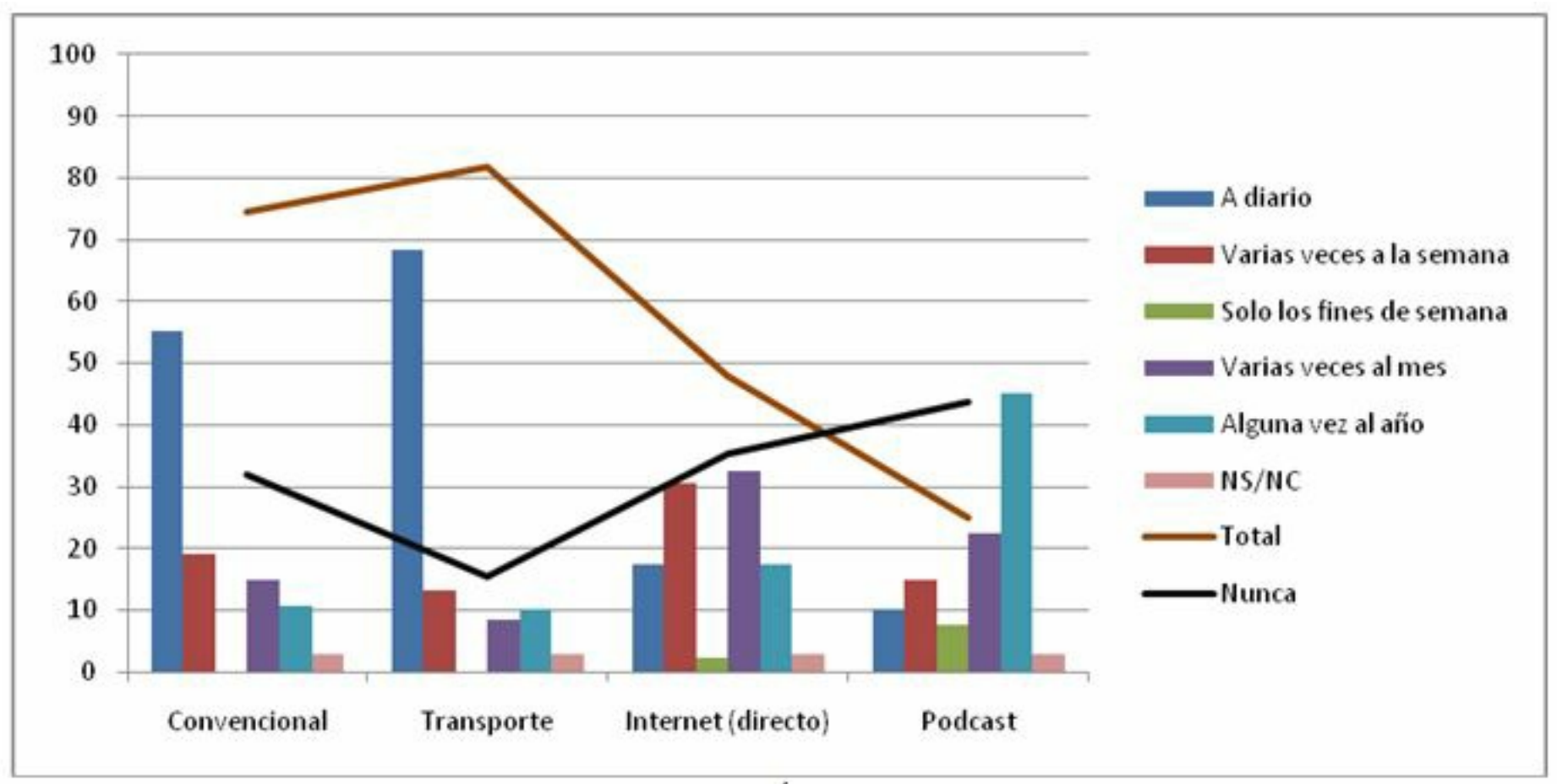

Fuente: elaboración propia

En ese sentido, el aparato radiofónico más utilizado es el del transporte, donde oyen la radio el $81,6 \%$ de los encuestados, de los cuales un $68,3 \%$ lo hacen de forma diaria. La radio convencional (6) ocupa el segundo lugar en popularidad, con un $74,4 \%$ de audiencia, un porcentaje muy superior al de quienes utilizan Internet para el consumo de este medio $(47,8 \%)$. 
En cuanto al momento seleccionado para encender la radio, destaca la mañana como franja horaria de mayor escucha. Un $84,7 \%$ de los profesores señalan aproximarse a la radio entre las 08:00 y las 12:00 horas, y preferentemente en el coche $(52,2 \%)$. Un $44,5 \%$ reconocen oír la radio entre las 12:00 y las 15:00, pero en este caso el medio favorito es Internet, con un $25 \%$ del total, frente al $14,8 \%$ que se decantan por el aparato clásico.

En relación al tipo de emisoras de preferencia, un $84,6 \%$ opta por la generalista, un $76 \%$ por la especializada en música y un $32,4 \%$ por la dedicada a deportes. En todos los casos el soporte más empleado es el aparato inserto en el medio de transporte. En concreto, el contenido más consumido por los docentes de La Salle y la BUAP es política nacional, elegida por un $63,4 \%$ de los encuestados - de estos, el $39,4 \%$ como primera preferencia-, le sigue cultura, escuchada por un 50,7\% de los encuestados e información local e información regional, por un $40,9 \%$ cada una de ellas.

Gráfico 5. Temáticas de preferencia para los docentes

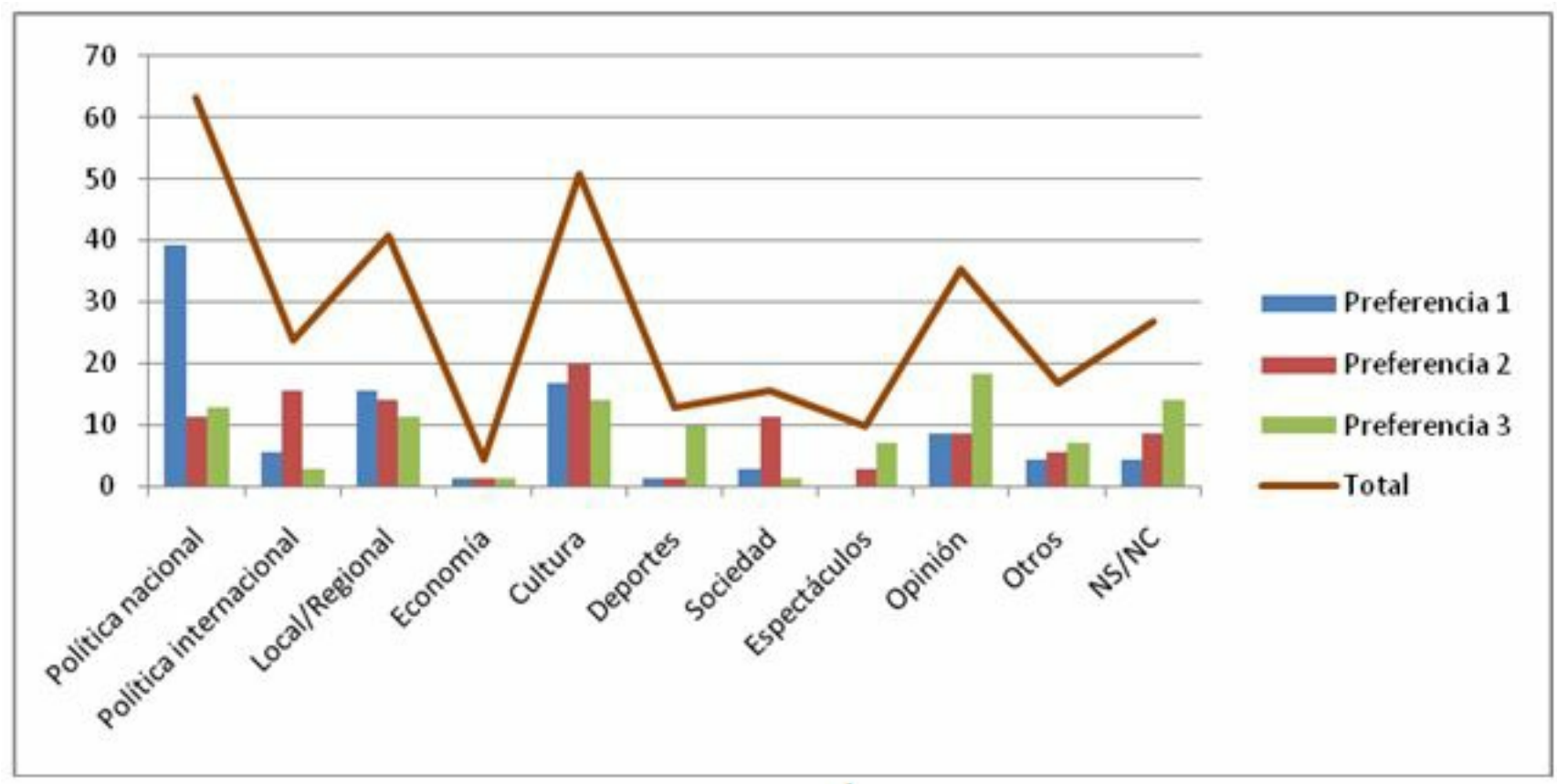

Fuente: elaboración propia

Cuando se pregunta por la calidad de la radio, una mayoría la perciben como buena (42,3\%) o regular (35,2\%). Las razones argüidas para no aplicar una mayor puntuación en este aspecto estaban motivadas por: los escasos medios económicos con los que cuenta la radio (31\%), la presencia de trabajadores poco preparados $(19,7 \%)$, la subordinación a intereses políticos $(14,1 \%)$ e intereses económicos $(11,3 \%)$ y corrupción $(7 \%)$.

Finalmente, los docentes destacaron los mecanismos de interacción que más acostumbran a utilizar para alzar su voz. Las opciones más señaladas tienen un carácter presencial, como es el caso del teléfono $(31,2 \%)$, mientras que la fórmula digital más empleada se corresponde con el uso de Facebook $(21,4 \%)$ y Twitter $(13 \%)$.

\subsection{Una televisión de baja estima y con una escasa interacción}

El profesorado universitario en Comunicación de México consume televisión nacional con una frecuencia principalmente diaria $(39,4 \%)$ y varias veces a la semana $(22,5 \%)$. A pesar de todo, aproximadamente uno de cada diez reconoce no nutrirse nunca de sus contenidos. El seguimiento de la televisión internacional es ligeramente menor, aunque el $32,4 \%$ se interesa por ella a diario y el $29,6 \%$ varias veces a la semana, mientras que el $14,1 \%$ admite no consumirla. En el caso de la televisión regional y local la frecuencia más repetida es la de alguna vez al año, en el $29,6 \%$ y el $21,1 \%$, respectivamente. También es significativo el porcentaje de profesores, cercano al 30\%, para el que la televisión local y regional no representa una opción de consumo.

Gráfico 6. Hábito de consumo según el tipo de televisión 


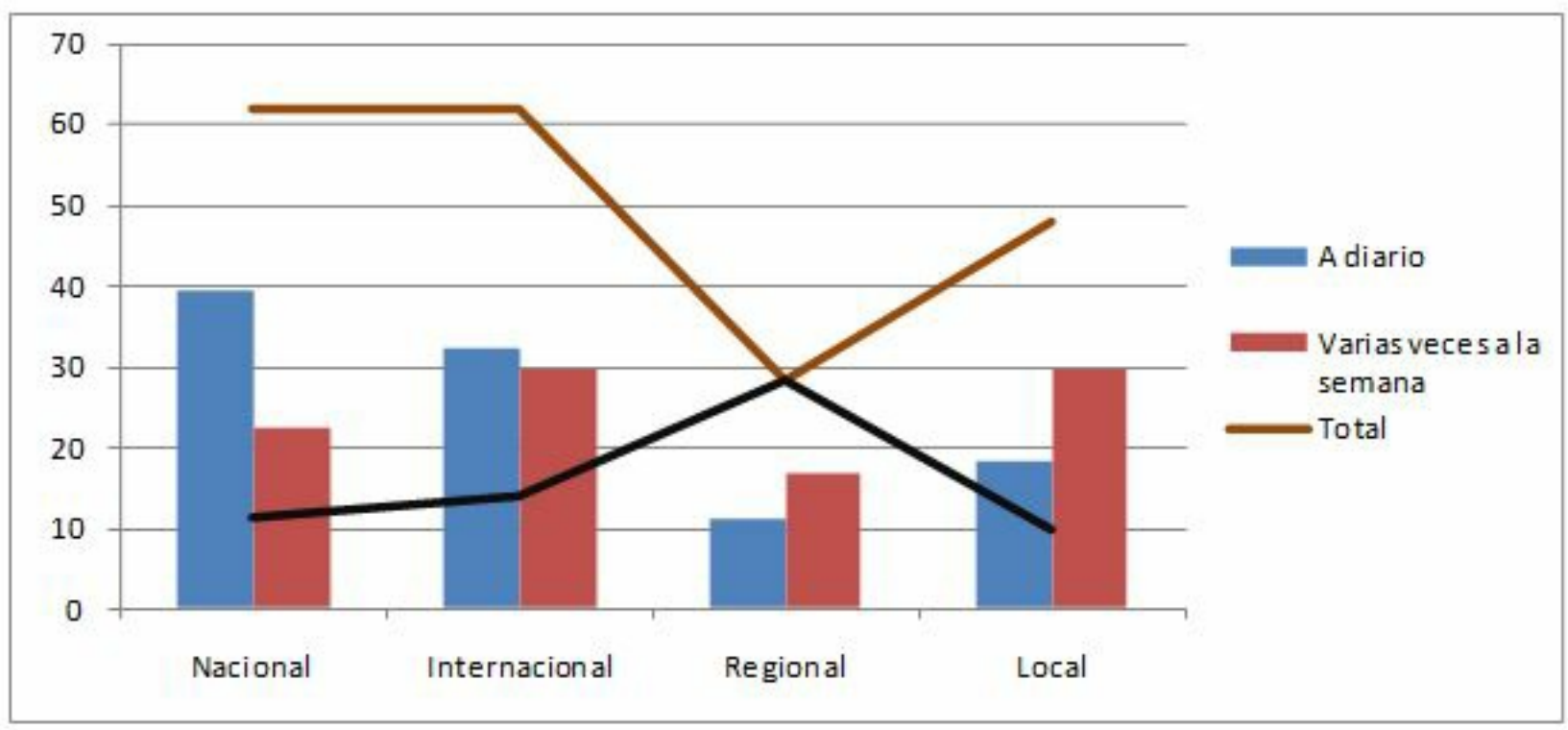

Fuente: elaboración propia

Cuando la televisión se visiona en familia, el soporte más utilizado es el aparato tradicional $(67,6 \%)$ que despunta muy por encima del resto de opciones. Semejantes respuestas se obtienen cuando la situación formulada es la de ver la televisión en soledad. De todo ello se desprende que la penetración de nuevas pantallas, más novedosas y ligadas a las últimas tecnologías como son los dispositivos móviles, tabletas o pantalla del ordenador, resulta anecdótica. Además, se comprueba que casi el $60 \%$ de los encuestados no tiene como hábito ver la televisión con amigos.

El momento del día en el que más docentes universitarios se aproximan a la televisión -concretamente, un $63,4 \%-$, es en la noche, en la franja que va desde las 22:00 a las 00:00 horas. Y es que las tasas de visionado por la mañana, de 8:00 a 12:00 y de $12: 00$ a $15: 00$ se sitúan en el $46,5 \%$ y en el $23,9 \%$, respectivamente, mientras que por la tarde, y concretamente de 15:00 a 19:00 horas y de 19:00 a 22:00 horas, la cifra de consumo cae hasta el $26,8 \%$ para volver a despuntar, en el último tramo de la tarde al 52,1\%. Lo que sí que se mantiene constante, sea cual sea la franja horaria explorada, es el uso prioritario -siempre con tasas superiores al $50 \%$, de entre quienes admiten consumirla- del aparato tradicional de televisión como soporte para ver la programación.

Gráfico 7. Soporte y momento de consumo televisivo

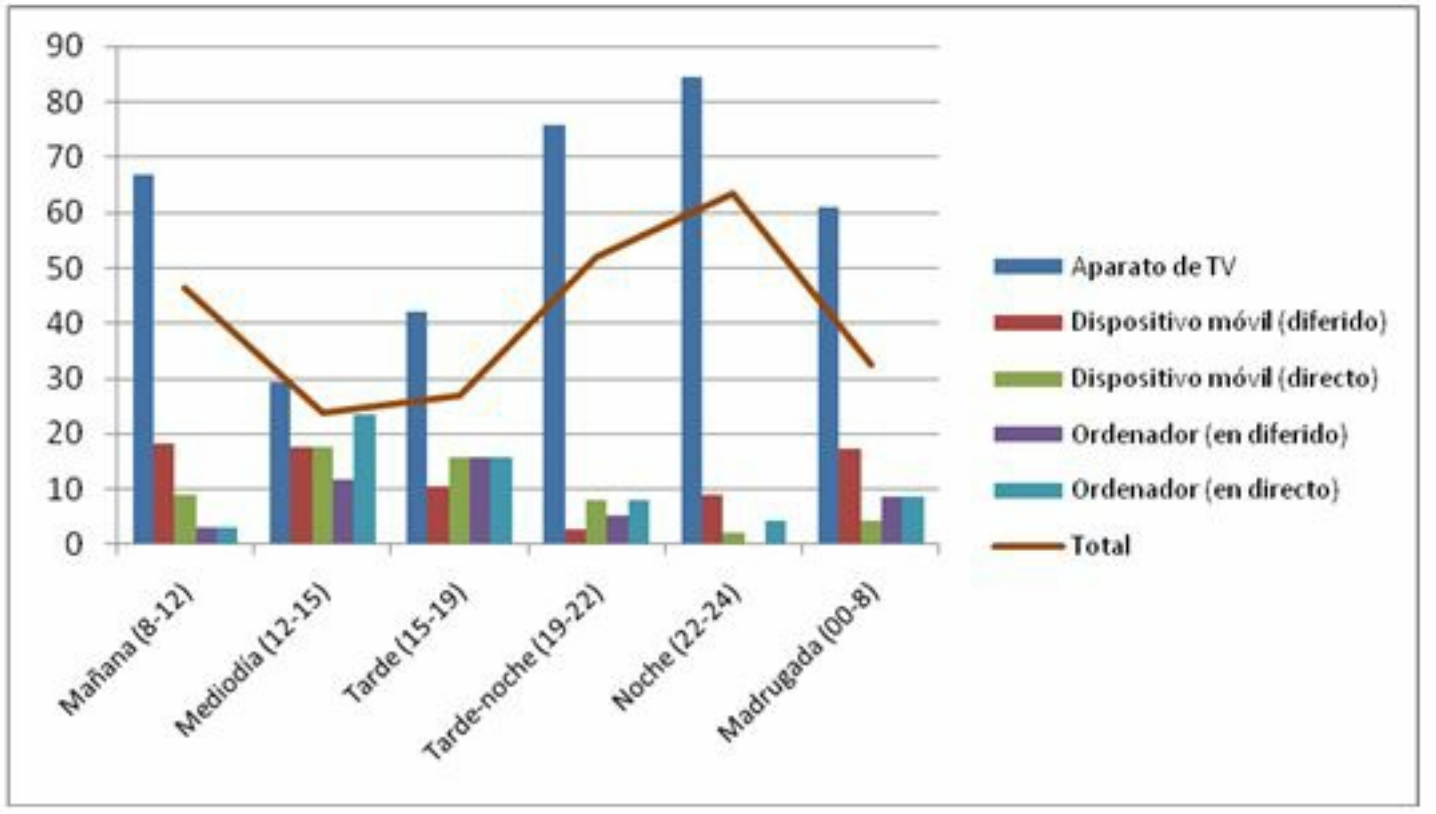


Fuente: elaboración propia

Los contenidos de tipo informativo que despiertan un mayor interés entre el profesorado son política nacional, primera opción de preferencia para uno de cada tres encuestados; seguido muy de cerca por cultura, categoría que se impone como segunda $(22,5 \%)$ y tercera opción de preferencia $(21,1 \%)$.

La calidad atribuida a la televisión es preferentemente mala o muy mala $(52,1 \%)$, seguida de regular $(31 \%)$, mientras que el porcentaje que la considera buena o muy buena ronda el $17 \%$. Los problemas señalados por más de la mitad de los profesores mexicanos, como causantes de su baja estima se refieren a la corrupción y a los intereses económicos y políticos que rodean al medio televisivo.

A la hora de hablar de participación, más de la mitad de los encuestados reconoce abiertamente que nunca ha interactuado con la televisión. Quienes sí que lo han hecho $(42,2 \%)$, han optado mayoritariamente por Facebook $(36,7 \%)$, por la participación presencial $(30 \%)$ y por el teléfono $(26,7 \%)$.

\subsection{Internet, las redes sociales como fuente de información}

En comparación con el resto de medios analizados, hay que tener en cuenta que Internet presenta un mayor número de posibilidades de acceso a la información, con independencia del medio de comunicación donde se publique en origen. Así pues, un 71,9\% consulta cibermedios y con un resultado muy parejo, se sitúa la lectura del perfil en redes sociales de amigos $(59,2 \%)$ y de medios de comunicación y determinados periodistas (55\%) como alternativa para estar al tanto de la actualidad. También resulta llamativo que el $40,8 \%$ descarte a los blogs y el 35,2\% a WhatsApp como una opción habitual de suministro de información.

En cuanto al lugar preferido para entrar en contacto con la información a través de Internet, un 97,9\% de los docentes aseveran hacerlo en el propio hogar y especialmente a través del portátil $(43,7 \%)$. En un porcentaje similar, el $94,6 \%$ señala conectarse en la universidad, también desde un ordenador portátil $(32,8 \%)$, un equipo de sobremesa $(29,8 \%)$ y el móvil $(28,3 \%)$. En relación a la franja horaria más utilizada para el consumo de contenidos digitales destaca el periodo comprendido entre las 08:00 y 12:00 seleccionado por un 78,9\% de los profesores de La Salle y la BUAP, en el cual, el $35 \%$ se hace valer del portátil y el $25 \%$ del móvil.

Gráfico 8. Frecuencia de consumo de Internet

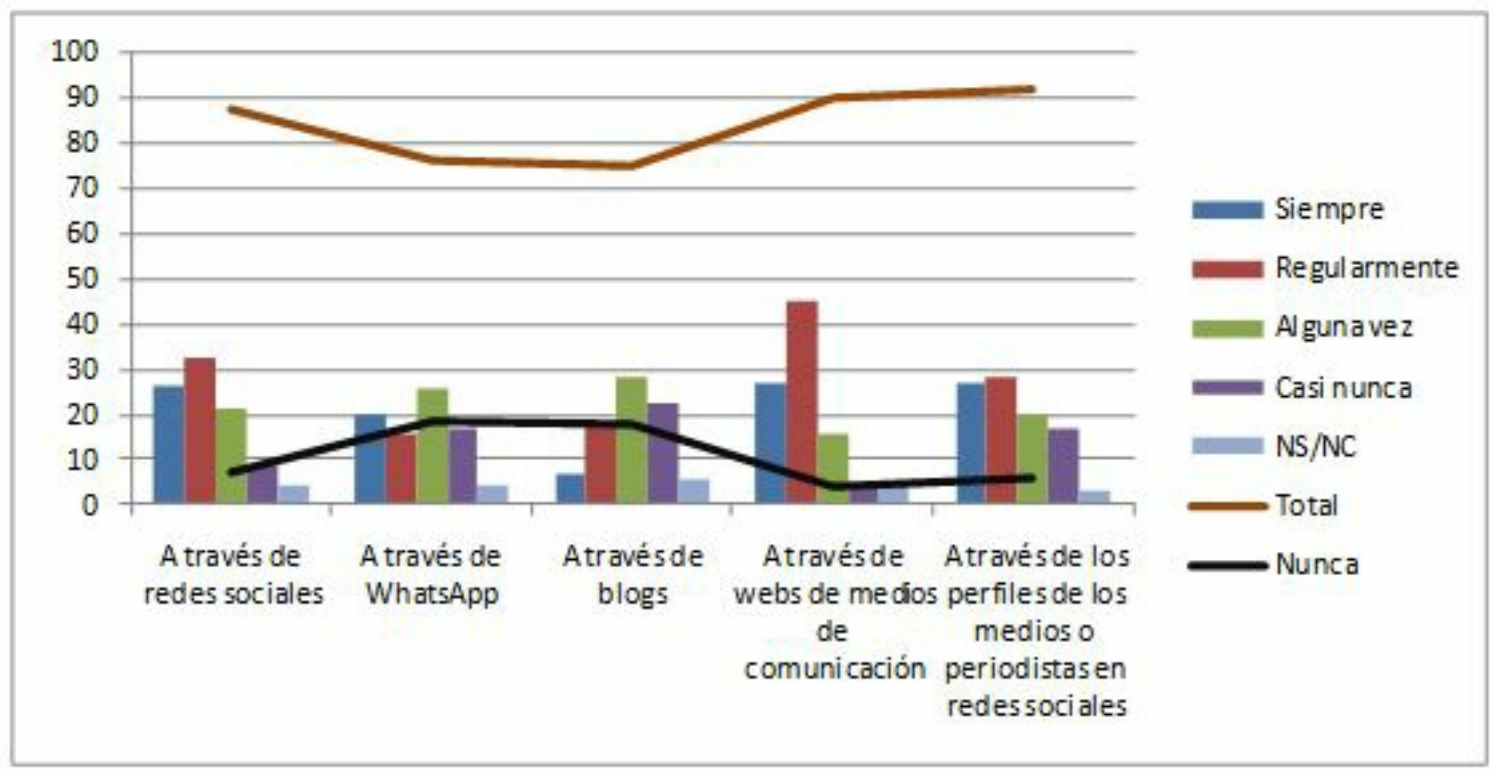

Fuente: elaboración propia

La información más consultada es la nacional, a la que acceden un 93,1\% de los docentes mexicanos, 73,2\% de forma diaria. Un $90,3 \%$ buscan información regional, el $45,1 \%$ diariamente y $21,1 \%$ varias veces semana. Un $89 \%$ consumen información internacional, a diario $(55,3 \%)$ y varias veces a la semana $(28,2 \%)$. Finalmente, un $86,2 \%$ se decanta por información local, sobre todo a diario $(45,1 \%)$, pero también varias veces a la semana y al mes $(16,9 \%$ en ambos casos). 
En una categorización por secciones clásicas aplicada a los cibermedios, se comprueba que política nacional sigue siendo la información preferida por un $78,9 \%$ del profesorado, de los cuales $46,5 \%$ lo seleccionaron como primera opción. Cultura es la segunda área temática más consultada, por un $54,9 \%$ del total; un $43,7 \%$ se decanta por política internacional, y un $38,5 \%$ por opinión.

En el momento en el que se pide al encuestado que mencione los tres sitios web principales que maneja más asiduamente para informarse en Internet, los nombres propios facilitados cercioran el importante influjo de los medios sociales como fuentes de información para los profesores mexicanos.

Gráfico 9. Sitios web más visitados por el profesorado

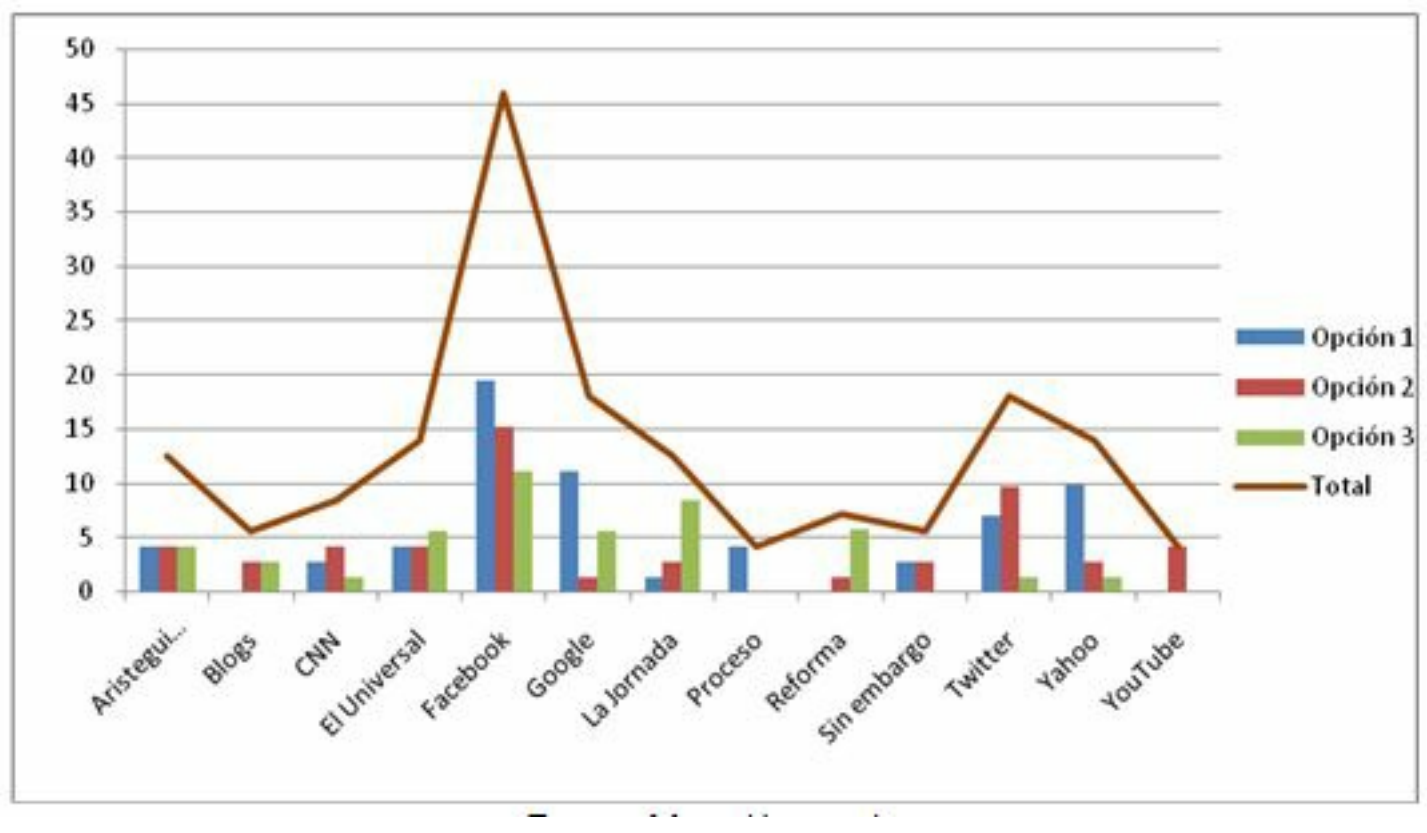

Fuente: elaboración propia

Tal y como se aprecia en el gráfico 9, un 46\% utiliza Facebook y un 18,1\% Google y Twitter para estar al día. El primer medio de comunicación mencionado se corresponde con la web de El Universal, señalado por el $14 \%$ de los docentes. El mismo porcentaje obtiene Yahoo, y posteriormente, se encuentra La Jornada y 'Aristegui Noticias' que logran un $12,6 \%$ de las consultas totales a cibermedios.

En última instancia, las formas de participación más populares en Internet entre los docentes mexicanos son los comentarios en noticias $(23,5 \%)$, la realización de encuestas (19,4\%), la interacción en redes sociales $(19,4 \%)$ y la publicación en foros $(14,1 \%)$. Como se aprecia, porcentajes bajos que no alcanzan a un tercio de la muestra.

\section{CONCLUSIONES}

El nivel de desarrollo de un país depende tanto del grado de penetración de las nuevas tecnologías como del uso que a estas se les dé. Como se ha podido comprobar a lo largo del marco teórico, Internet previene la manipulación ideológica, generaliza la participación del ciudadano y alza su voz. En definitiva, consolida los pilares de la democracia. Así, se entiende que gran parte de las políticas llevas a cabo por los gobiernos para extender las TIC integren, como componente fundamental, la educación.

Si bien es cierto que la función del docente está ligada a la transmisión de conocimientos, la necesidad imperiosa en nuestra actual sociedad de la información de dominar las innovaciones tecnológicas le convierten, además, en un modelo a imitar en cuanto al uso que haga de ellas. De ahí que, a través de esta investigación se supervisen los hábitos de consumo mediático de un colectivo especialmente interesado por el producto informativo y su convergencia, el docente del área de Comunicación.

Además, hay que tener en cuenta que el panorama mediático en México presenta unas particularidades 
propias, forjadas a lo largo del tiempo, que condicionan su devenir y contenido final y entre las que destacamos: su fuerte capacidad de influencia sobre la población, la concentración empresarial ejemplificada en el dominio de Televisa y la ineficiente regulación pública.

Ante esta situación, y haciendo uso de la técnica de la encuesta, se interroga a los docentes de dos centros universitarios mexicanos, La Salle, en Ciudad de México, y la BUAP, en Puebla, sobre la calidad de los contenidos generados por los distintos medios (prensa, radio, televisión e Internet) y los problemas que los acechan; las temáticas que más atraen su atención; las cabeceras y programas que más consumen; los soportes utilizados durante el visionado y hábitos de consumo -ejemplificado principalmente a través del lugar y horario de lectura, escucha o visionado-.

El $60 \%$ de la plantilla universitaria contestó a la encuesta y de sus respuestas se extrae que el interés de este colectivo por consumir medios es máximo: todos los medios de comunicación -prensa, radio y televisiónpresentan una tasa de consulta diaria que afecta a más del $40 \%$ de los entrevistados. La excepción viene de la mano de las revistas, cuya lectura se pospone prioritariamente a varias veces al mes.

El medio de comunicación preferido para informarse es la radio, seguida de la televisión y la prensa. Y cuando se trata de averiguar los mecanismos más utilizados en la Red, despunta, con más de la mitad de los encuestados, la consulta a cibermedios y a los perfiles en redes sociales tanto de amigos y conocidos como de periodistas y medios de comunicación.

Por lo que se refiere a la prensa, la percepción de su calidad entre el colectivo docente universitario es buena o muy buena; las principales secciones de interés se localizan en política nacional, internacional y cultura; y $L a$ Jornada resulta la cabecera leída con más asiduidad. En torno al $80 \%$ de los encuestados reconoce haber interactuado en algún momento con el medio impreso siendo la opción de compartir noticias a través de las redes sociales la opción más marcada $(75,4 \%)$.

En radio, los niveles de interactividad de carácter presencial y virtual se encuentran igualados. Sin embargo, el aparato radiofónico más extendido es el tradicional, ya sea en el transporte $(84,5 \%)$ o en el hogar $(65,2 \%)$. El tipo de emisora preferida es la generalista, donde habitualmente escuchan política nacional, cultura o información local y regional. Además, el medio goza de una buena percepción entre los docentes, pues el $42,3 \%$ de estos la consideran de buena calidad. Sin embargo, la penetración de la radio online o la escucha de contenidos bajo demanda (podcast) presenta una escasa incidencia.

En el medio televisivo llama la atención la reticencia, de uno de cada diez, a nutrirse de sus contenidos, muy posiblemente por la baja calidad que se le asocia. Y es que el $52 \%$ de los docentes califica a la televisión como mala o muy mala. Quienes sí que se aproximan a ella lo hacen fundamentalmente a través del aparato tradicional. El resto de posibilidades, -lo que llamamos tercera y cuarta pantalla-, móvil, tableta u ordenador dispone de un nivel de aceptación que roza lo anecdótico. Y el horario en el que se concentra un mayor consumo televisivo se sitúa en la tarde-noche, entre las 19:00 y las 00:00 horas, cuando en torno al 50\% de los encuestados reconoce encenderla.

Internet demuestra un cambio en las nuevas formas de consumo de actualidad informativa. En este sentido, resulta llamativo el influjo de las redes sociales en sustitución de los medios tradicionales: Facebook, Google y Twitter se sitúan como las opciones preferidas para el acceso a la información entre los docentes mexicanos, donde consultan habitualmente política nacional, cultura, política internacional y opinión. A pesar de este distanciamiento con medios concretos, muestra de unos usuarios más transversales en la búsqueda de información, la forma de interacción más común sigue relacionada con los medios tradicionales, concretamente con los comentarios en noticias $(23,5 \%)$.

Estos resultados manifiestan una presencia incipiente de Internet en el panorama mediático mexicano y por extensión, latinoamericano, y no tanto un dominio de sus dispositivos y posibilidades, lo que obliga a apostar por la enseñanza en destrezas de comunicación digital, incluido en el ámbito universitario. 


\section{Agradecimientos}

Este estudio se enmarca dentro del Proyecto de Innovación Docente: Evaluación y Desarrollo de Metodologías Docentes en Comunicación y Competencia Mediática amparado por la Universidad de Valladolid. Asimismo, se reconoce el valor de las estancias financiadas por el Banco Santander en Ciudad de México y por la Benemérita Universidad Autónoma de Puebla en Puebla.

\section{REFERENCIAS BIBLIOGRÁFICAS}

AMIPCI. Asociación Mexicana de Internet (2015): $11^{\circ}$ estudio sobre los hábitos de los usuarios de internet en México 2015. Recuperado de: https://www.amipci.org.mx/images/AMIPCI_HABITOS_DEL_INTERNAUTA_MEXICANO_2015.pdf

APARICI, R., \& OSUNA, S.: Educomunicación y cultural digital. En APARICI, R. (2010): Educomunicación: más allá del 2.0. Barcelona: Gedisa, pp.307-316.

BARJA, G., \& GLIGLER, B.: El concepto de pobreza de información y cómo medirlo en el contexto latinoamericano. En GALPERIN, H., \& MARISCAL, J. (2009): Pobreza digital. Perspectivas de América latina y el Caribe. Ciudad de México: Cide, pp.19-46.

CESOP. Centro de Estudios Sociales y de Opinión Pública (2014): Encuesta telefónica sobre confianza en las instituciones. Recuperado de:

http://www5.diputados.gob.mx/index.php/esl/content/download/15513/78080/file/58-confianza-instituciones.pdf

CONSEJO NACIONAL PARA LA CULTURA Y LAS ARTES. (2011): Encuesta nacional de hábitos, prácticas y consumos culturales 2010. Recuperado de: http://www.conaculta.gob.mx/encuesta_nacional/

ESTEINOU MADRID, J.: "Globalización, medios de comunicación y cultura en México a principios de siglo XXI". Revista Latina de comunicación social, vol. 42 (2001), n 4.

FERNÁNDEZ CHRISTLIEB, F. (2005): Los medios de difusión masiva en México. Ciudad de México: Ediciones Casa Juan Pablos.

GARCÍA, M. \& LLOPIS, R.: La encuesta. En GARCÍA FERRANDO, M. et al. (comps.) (2015): El análisis de la realidad social: métodos y técnicas de investigación (4ª ed.). Madrid: Alianza editorial, pp. 331-362.

HUERTA-WONG, J. E., \& GÓMEZ, R.: "Concentración y diversidad de los medios de comunicación y las telecomunicaciones en México". Comunicación y sociedad, nº 19 (2013), pp. 113-152.

INEGI. Instituto Nacional de Estadística y Geografía (2015): Encuesta Intercensal 2015. Recuperado de: http://www.inegi.org.mx/est/contenidos/Proyectos/encuestas/hogares/especiales/ei2015/

LAGUNES-DOMÍNGUEZ, A., TORRES-GASTELÚ, C.A., FLORES-GARCÍA, M.A. \& RODRÍGUEZ-FIGUEROA, A.: "Comparativo del uso de Tecnologías de la Información y Comunicación (TIC) por profesores de dos universidades públicas de México". Formación universitaria, vol. 8 (2015), n² 2. doi: http://dx.doi.org/10.4067/S0718-50062015000200003

LEGORBUR HORTELANO, J.M (Coord.) (2013): Modelos de convergencia de medios en España I: digitalización, concentración y nuevos soportes. Madrid: CEU Ediciones.

LEÓN VÁZQUEZ, S.: Sociedades en transición democrática y comunicación pública: el caso de Aguascalientes, México. En DETTLEFF, J. A., CAÑIZÁLEZ, A. Y OLIVERA, L. C. (2001): Política y comunicación: democracia y elecciones en América Latina. Perú: Universidad Católica del Perú, pp. 63-82.

LUGO, M. T.: "Las políticas TIC en la educación de América Latina. Tendencias y experiencias". Revista Fuentes, no 10 (2010), pp. 52-68. 
MARTÍNEZ SANZ, R., ISLAS CARMONA, O., CAMPOS DOMÍNGUEZ, E., \& REDONDO GARCÍA, M.: "EI profesor universitario de Comunicación: acceso, consumo y cultura mediática. Un estudio comparativo entre España y México". Revista Latina de Comunicación Social, nº 71 (2016), pp. 349-372.

MENESES ROCHA, M. E.: Periodismo: desafíos para su libre ejercicio. En BRAVO, J., VEGA MONTIEL, A. \& TREJO DELARBRE, R. (2011): Panorama de la comunicación en México. Desafíos para ala calidad y la diversidad. Ciudad de México: Asociación Mexicana de Derecho a la Información, pp.195-208.

MORAES, D., \& KILLMANN, M. E. (2011): La cruzada de los medios en América Latina: gobiernos progresistas y políticas de comunicación. Buenos Aires: Paidós.

ONU (2014). E-Government for the future we want. Nueva York: Economic \& Social Affairs.

ORGANIZACIÓN DE LOS ESTADOS AMERICANOS (2010). El Informe Anual de la Comisión Interamericana de Derechos Humanos 2010. Recuperado de:

https://www.cidh.oas.org/annualrep/2010sp/RELATORIA_2010_ESP.pdf

PASQUIALI, A.: Diversidad es fecundidad y democracia. En TREJO DELARBRE. R. \& VEGA MONTIEL, A. (2011): Diversidad y calidad para los medios de comunicación: diagnósticos y propuestas, una agenda ciudadana. México: Asociación Mexicana de Derecho a la Información.

ROSAS MANTECÓN, A.: Los estudios sobre consumo cultural en México. En MATO, D. (coord.) (2002): Estudios y Otras Prácticas Intelectuales Latinoamericanas en Cultura y Poder. Caracas: Consejo Latinoamericano de Ciencias Sociales (CLACSO), pp. 255-264.

SÁNCHEZ RUIZ, E.: "Los Medios de Comunicación Masiva en México, 1968-2000". En BIZBERG, I. \& MEYER, L. (2005): Una historia contemporánea de México. Ciudad de México: Océano de México, pp. 403-552.

SÁNCHEZ RUIZ, E.: "Centralización, poder y comunicación en México”. Comunicación y Sociedad, vol. 1 (1987), n 3, pp.11-51.

SCHALK QUINTANAR, A. E.: El impacto de las TIC en la educación. En AA.VV (2010): Relatoría de la Conferencia Internacional de Brasilia, 26-29 abril de 2010. Unesco.

SOSA PLATA, G.: Grupos radiofónicos y concentración. En TREJO DELARBRE, R.; VEGA, A. \& BRAVO, J. (2010): Panorama de la comunicación en México 2011. México: AMEDI y Cámara de Diputados, pp. 97-114.

TREJO DELARBRE, R.: México: Medios, Política y Ciudadanos en la hora de la Convergencia Digital. En: SORJ, B. (2012): Democracia y medios de comunicación. Más allá del Estado y el mercado. Buenos Aires: Centro Edelstein de Pesquisas Sociais y Konrad Adenauer Stiftung, pp. 191- 221.

UNESCO (2013): Uso de tic en educación en América Latina y el Caribe. Análisis regional de la integración de las TIC en la educación y de la aptitud digital (e-readiness). Québec: Instituto de estadística de la Unesco.

VILLAMIL, J. (2012): El sexenio de Televisa: Conjuras del poder mediático. México: Grijal.

(1) Si bien es cierto que en el segundo semestre de 2014 esta ley queda derogada por la denominada Ley Federal de Telecomunicaciones y Radiodifusión, el fuerte control del espectro radioeléctrico se perpetúa.

(2) Estos grupos radiofónicos son: Radiorama, Grupo Acir, Radiocima, Organización Impulsora de Radio, Sociedad Mexicana de Radio, Promosat de México, Radiodifusoras Asociadas, MVS Radio, Organización Radio Fórmula y Multimediao Estrellas de Oro.

(3) Un estudio realizado en 2010 por el Consejo Nacional para la Cultura y las Artes de México (Conaculta) 
reveló que el $38 \%$ de la población encuestada no lee periódicos y el 49 \%, revistas.

(4) El promedio mundial es de 23,57 abonados por cada 100 habitantes (ONU, 2014).

(5) Según datos aportados por el INEGI (2015).

(6) Al utilizar el adjetivo convencional nos referimos al tipo de soporte, el transistor.

\section{BREVE SEMBLANZA DE LAS AUTORAS}

Raquel Martínez Sanz. Profesora Ayudante Doctor en el Grado de Periodismo de la Universidad de Valladolid. Miembro del Grupo de Investigación Reconocido NUTECO (Nuevas Tendencias en Comunicación). Sus líneas de investigación se orientan hacia la comunicación corporativa y los efectos de los nuevos medios digitales y su consumo. Premio de Investigación del CES de Castilla y León (2015). Autora de distintos artículos publicados en revistas indexadas como: Revista de Documentación Científica, RLCS, El Profesional de la Información o Telos.

Dafne Calvo. Premio Extraordinario de Máster en Investigación de la Comunicación y de Grado en Periodismo por la Universidad de Valladolid. Ha trabajado como profesora visitante en la Benemérita Universidad Autónoma de Puebla (México) y pertenece al equipo de trabajo del Proyecto I+D "Las estrategias de campaña online de los partidos políticos españoles: 2015-2016” (Universidad Complutense de Madrid). En la actualidad, realiza su tesis doctoral en Comunicación y Participación política digital.

Ámbitos. Revista Internacional de Comunicación, n.35, edición de invierno, 2016-2017.

Recibido: 18/09/2016

Aprobado: 07/12/2016 